\title{
Food consumption on medical elderly wards
}

\author{
T. McDougall ${ }^{1}$, H. Williams ${ }^{1}$ and J. Fairbrother ${ }^{2}$ \\ ${ }^{1}$ Department of Nutrition and Dietetics, Castle Hill Hospital, Castle Road, Cottingham, East Yorkshire HU16 5JQ, UK and \\ ${ }^{2}$ Department of Nutrition and Dietetics, Pinderfields General Hospital, Aberford Road, Wakefield, WF1 4DG, UK
}

There is much concern about malnutrition in hospitalized elderly people; malnutrition on admission to hospital is more prevalent in the older patient ( $\geq 65$ years) than in the younger adult ${ }^{(1)}$. Following a local study investigating the effect of improving meal provision on the nutritional and functional status of patients on elderly wards ${ }^{(2)}$, Hull \& East Yorkshire Trust had already implemented a fortified diet, protected meal times and a red tray system. However, in response to Hungry to be Heard ${ }^{(3)}$, the Trust started to consider the use of volunteers to provide support at meal times on the elderly wards.

An audit was conducted to provide baseline information for comparison to measure the impact that volunteers may have on oral intake and also to identify roles in which volunteers may provide effective support at meal times. The weight of food delivered, served and wasted was recorded over two lunch and two supper services on four medical elderly wards, over an 8 week period. The amount of food consumed (by weight) was then calculated and patient satisfaction was measured.

On average, $76 \%$ (by weight) of plated food served to the elderly patients was consumed. However, only $57 \%$ (by weight) of the food supplied to the ward was actually plated; $43 \%$ (by weight) of the total food was wasted without being served. The patient satisfaction survey $(n=40)$ revealed areas of dissatisfaction (negative responses $>10 \%)$ regarding portion size, temperature and time to eat.

Originally, it was envisaged that volunteers would be used to feed the patients; however, the findings of this audit suggest that they may be more effectively used to improve the eating environment and provide encouragement, ensure correct portion size and offer 'second servings' and assist with food service to prevent the serving of cold meals. There is potential to reduce wastage and improve cost effectiveness. Since on average, only $75 \%$ of the plated food was consumed, it may also be of benefit to increase the nutritional content of the food to ensure that minimum nutritional requirements can be met with $75 \%$ intake.

We focused our audit on the medical elderly wards; however, with an ageing population, the proportion of elderly patients in hospital is growing and meal provision in areas such as stroke and orthopaedics is likely to face similar issues.

1. BAPEN (2009) Nutrition Screening Survey in the UK in 2008. BAPEN website.

2. McDougall T, Hannah J, Baranidharan S et al. (2006) Preventing malnutrition in elderly hospitalised patient by using food as treatment. Proc Nutr Soc 65, 19A.

3. Age Concern (2006) Hungry to be Heard. Age Concern England. 